\title{
Yellow Fever Virus Infection
}

National Cancer Institute

\section{Source}

National Cancer Institute. Yellow Fever Virus Infection. NCI Thesaurus. Code C35547.

A viral infection caused by a flavivirus called yellow fever virus. It is transmitted to humans from infected mosquitoes. The signs and symptoms range from a mild febrile illness to liver damage with jaundice and hemorrhages. 